\title{
ON AN INITIAL AND NONLOCAL INTEGRAL BOUNDARY CONDITION FOR A MIXED TYPE EQUATION
}

\author{
Khanlar Mamedov ${ }^{1}$ and Veysel Kılınç ${ }^{1}$ \\ ${ }^{1}$ Mersin University
}

July 30, 2020

\begin{abstract}
On an initial and boundary value problem for a mixed type equation is considered. A uniqueness theorem for the solvability of this problem is shown and constructed the solution as the sum of Fourier series. The stability of the solution with respect to initial function is proved.
\end{abstract}

\section{Hosted file}

Manuscript by Kh. R. Mamedov and V. Kilin\selectlanguage\{ngerman\}ç.pdf available at https://authorea.com/users/308444/articles/473205-on-an-initial-and-nonlocal-integralboundary-condition-for-a-mixed-type-equation 